\title{
Kwitara Santayá u'wbohiná-kueshro. Con-jugando patrimonios corporales ancestrales en Bogotá: territorio muisca de Bosa.
}

\section{Jairzinho Francisco Panqueba Cifuentes Profesor-investigador en la Secretaría de Educación Distrital, Colegio San Bernardino, territorio Muisca de Bosa en Bogotá, Colombia. Catedrático en la Universidad Pedagógica Nacional, Facultad de Educación Física. panqueba@gmail.com}

Resumen: El escrito presenta la sistematización que en el territorio muisca de Bosa hemos logrado al seguir cuatro caminos de con-jugaciones de los patrimonios corporales ancestrales. El primer camino es el de las ancestras y los ancestros que nos dejaron el cuerpo como ofrenda portadora de saberes milenarios. El segundo son los con-juegos multiculturales de las danzas y las músicas. El tercero es el del juego del tejo, hecho metodología de investigación desde las interculturalidades de Bogotá. El cuarto es el de nuestros resultados, reflejados en la con-jugación de patrimonios corporales ancestrales muiscas y mayas. Finalmente compartimos los destinos posibles, las con-jugaciones latentes y otros senderos por andar.

Palabras clave: patrimonios, corporalidad, ancestral, interculturalidades, juego, educación 


\section{Introducción}

Kwitara Santayá u'wbohiná-kueshro es una frase en u'waka, idioma practicado actualmente por el pueblo indígena u'wa que habita el territorio de la sierra nevada del cocuy, departamentos de Boyacá, Arauca y Norte de Santander (Colombia). Traducida literalmente al castellano, se leería: en Bogotá jugando juntos. Alude a la experiencia de jugar comunitariamente en Bogotá, territorio del pueblo indígena muisca, que como el u'wa, también hace parte de la familia lingüística chibcha. Santayá es el nombre u'wa para la capital de Colombia. Kwitara es una preposición de lugar y también de destino. U'wbohiná expresa actividad de un grupo de personas, a partir de la fusión de las palabras: uhboiná y u'wa. La primera denota una acción o labor compartida, similar al término minga en nasayuwe, idioma del pueblo indígena nasa del departamento del Cauca, Colombia. La segunda significa persona o gente que sabe hablar. Finalmente, kueshro es una palabra usada para manifestar la acción de jugar. Para esta investigación significamos la citada frase en u'waka como: con-jugando en Bogotá.

Las con-jugaciones de esta investigación se ubican en el territorio muisca de Bosa, donde la comunidad educativa y el colegio San Bernardino han trenzado interculturalidades a través de juegos, bailes, arcillas, tejidos, músicas y otras posibilidades corporales. A continuación describimos cuatro caminos que hasta el momento nos han concedido confluir en la cuenca de los patrimonios corporales ancestrales. El primero es la con-jugación entre las fuentes que han estado mediando nuestra labor docente, de investigación y juego. El segundo son los con-juegos iniciales entre lenguajes ancestrales, juegos, danzas y músicas. El tercero ha sido el de las itinerancias territoriales del zepcuagoscua: juego del tejo o turmequé, como ejercicio de interculturalidades entre institución educativa y comunidad muisca de Bosa. El cuarto es el de las con-jugaciones entre zepcuagoscua y chaaj-juego de pelota maya-, dos innovaciones ancestrales de ceremonias, cosmovisiones, historias y contempraneidades corporales. Finalizando el escrito proponemos los destinos posibles, las con-jugaciones latentes y otros senderos por andar. 


\section{Kwitara remina sibara-aka cui bátaro wahnatará bajaká.}

Patrimonios corporales ancestrales es la frase en idioma castellano que mejor expresaría el título que en u'waka decidimos asignar al presente apartado. Desde las raíces lingüísticas, remina es la palabra para aludir a las generaciones antepasadas: las ancestras y los ancestros. Sibará- ojca son dos palabras que indistintamente se emplean para nombrar al cuerpo materia, pero ojca también habla de la materia y el alma: aka en idioma u'wa'. La expresión cui bátaro denota dejar herencia. Wahntará es el territorio de vida de la muerte, concepto cercano al inframundo maya o al hades griego. Bajaká es una ofrenda del alma, un legado simbólico que puede expresarse en objetos materiales para pagar una petición a Sira: deidad creadora en la cosmovisión u'wa. La expresión en profundidad significaría que las ancestras y los ancestros nos dejaron ofrendas en los cuerpos nuestros, pero que hay unas memorias circulando para alimentarnos material y espiritualmente. Es el cuerpo como ofrenda, pero también como portador de saberes milenarios.

Desde esta propuesta en cosmovisión u'wa, los patrimonios corporales ancestrales son las herencias de prácticas, ritos y estéticas de kueshro -juego- que han sido asumidas histórica y cotidianamente por las personas de manera individual y grupal frente a sus relaciones mutuas y con el entorno territorial de gentes y tierras. Estos patrimonios son una de las tantas formas de expresión de las diversidades humanas, en los que se destacan los juegos ancestrales y sus dimensiones rituales, ceremoniales, lúdicas, deportivas, recreativas e históricas. Son legados inmateriales que las comunidades, pueblos, familias y personas practican actualmente de diferentes maneras (Panqueba, et. Al., 2000 y 1997). Legados cuyos desusos también son formas de práctica, tanto como la movilización ritual tornada en exhibicionismo u otras variantes expresadas en formas folclóricas para distintos fines.

Considerando una delimitación equilibrada del tema, por lo menos dos cuestiones subyacen a esta propuesta conceptual. La primera está ligada con la noción de patrimonio cultural inmaterial, de antemano aceptada por los países miembros de la Organización de las Naciones Unidas para la Educación, la Ciencia y la Cultura UNESCO². La segunda se

\footnotetext{
'En la cosmovisión u'wa, hablar es un acto del alma. U'waka o idioma u'wa significa literalmente: el alma de la gente que sabe hablar.

${ }^{2}$ United Nations Educational, Scientific and Cultural Organization.
} 
ubica en el ámbito de los estudios sobre el cuerpo, las corporalidades y la educación física que han emergido de manera importante desde principios del siglo XXI.

Con respecto a la ubicación del tema en el ámbito del patrimonio cultural inmaterial, podemos decir que emerge del mismo sin ánimo de controvertirlo. Responde más bien a la ágil dinámica con la cual son asimilados los preceptos universales en los ámbitos locales. El patrimonio inmaterial surge desde la noción de derecho de propiedad sobre un bien cultural, concepto que luego va adquiriendo alcances polivalentes en concordancia con los usos y tradiciones propios de un territorio (Kurin, 2004: 68-70). Durante los siglos XIX y XX la idea de propiedad cultural es aprovechada inicialmente para imaginar los estados-nación y posteriormente para dotar los símbolos de las patrias republicanas. "Sin embargo, hoy en día el patrimonio ha de dar respuesta a nuevas imágenes identitarias, originadas tanto por la fragmentación de identidades que caracteriza nuestra sociedad, como a su valor de consumo como recurso económico" (Agudo, 2011: 3).

Actualmente, la "Convención para la salvaguardia del patrimonio cultural inmaterial"3, considera dos listados principales de reconocimiento al patrimonio intangible: La Lista representativa del patrimonio cultural inmaterial (artículo 16) y la Lista del patrimonio cultural inmaterial que requiere medidas urgentes de salvaguardia (artículo 17) ${ }^{4}$. Frente al carácter de las listas, valga resaltar algunos retos que evidencian los siguientes dos casos incluidos a partir del año 2008, cuando son aprobadas las directrices operativas de la Convención ${ }^{5}$. El primero, es la "Ceremonia ritual de los voladores", inscrita en la lista desde 2009 por México, pero que ha sido y es practicada en la región mesoamericana. En Guatemala por ejemplo se conoce como danza del palo volador, pero también como juego tradicional. La definición del patrimonio cultural inmaterial para su inclusión en la lista considera que: "La ceremonia ritual de los Voladores se ha transmitido de generación en generación y ha sido constantemente recreada por las comunidades interesadas en respuesta a su interacción con la naturaleza y el universo" (UNESCO, 2009: 63). Y pese a que exhibe un carácter lúdico

\footnotetext{
${ }^{3}$ La Convención se adoptó por la Conferencia General de la UNESCO en el 2003 y en la actualidad incluye 139 Estados Miembros.

${ }^{4}$ Solamente los países que han ratificado la Convención son elegibles para presentar candidaturas para su inscripción en las listas. Para conocer los procedimientos de postulación pueden consultarse los documentos oficiales (por ejemplo: UNESCO, 2008b).

${ }^{5}$ Desde la aprobación de las directrices operativas para la aplicación de la convención para la salvaguardia del patrimonio cultural inmaterial (UNESCO, 2008a), 167 elementos hacen parte de la lista representativa y 31 son los considerados para el listado de los que requieren medidas urgentes de salvaguardia.
} 
que es ritual y ceremonial desde sus formas y percepciones corporales, sus elementos constitutivos son tomados como manifestación cultural en la declaratoria (Ibíd.: 62).

El segundo caso en las listas es la tímida figuración de los juegos y las danzas que recurrentemente hacen parte de festividades declaradas patrimonio intangible. Si bien algunas danzas figuran de manera específica en las listas, otras son invisibles porque hacen parte de eventos carnavalescos o también de algunas ceremonias. En el caso de los juegos, a la fecha ninguno ha sido objeto de declaratoria. Esto parece estar visibilizándose en el mismo ámbito de la Convención, gracias a una tercer medida de salvaguardia considerada en su artículo 18: Los "Programas, proyectos y actividades para la salvaguardia del patrimonio que reflejen del modo más adecuado los principios y objetivos de la Convención”. De diez registros aceptados desde 2008 como mejores prácticas de salvaguardia (artículo 18 de la Convención), hay uno que hace manifiesta la urgencia de las corporalidades como patrimonio: A programme of cultivating 'ludodiversity': safeguarding traditional games in Flanders ${ }^{6}$.

Para el análisis que venimos haciendo, el concepto ludodiversity resulta pertinente porque ofrecería una visión de patrimonio como perspectiva cultural en conjugación con el patrimonio como perspectiva corporal:

Un concepto clave que se utiliza en este método de protección es el de 'ludodiversidad' (del latín ludus, juego), que se refiere a una amplia variedad de actividades recreativas como juegos, deportes, ejercicios físicos, danza y acrobacias dentro de una relativamente gran área geográfica. Los ejemplos incluyen flamencos tiro deportivo (papagayo, arco, ballesta y culebrina), juegos de tazón (krulbol, Trabol, beugelen y kegelen) y juegos de pelota, algunos documentados entre los siglos XIII y XIV (UNESCO, 2012: 12)

Aunque la definición del concepto presenta una tendencia a inventariar las prácticas, es importante la noción de patrimonio vivo a partir de un trabajo de investigación, difusión y apropiación contemporánea de los juegos. Ello les permite preguntarse: "En la era de los Juegos Olímpicos y con la proliferación de los deportes modernos, ¿Cómo pueden los juegos y deportes tradicionales ser vigorizados como patrimonio vivo de hoy?"8. En concordancia con los dinámicos florecimientos de las diversidades culturales, la conjugación

\footnotetext{
6 "Programa para cultivar la ludodiversidad: salvaguardia de los juegos tradicionales en Flandes".

${ }^{7}$ Traducción propia.

8 Ídem.
} 
de elementos respectivamente contemporáneos con sus hechos históricos, ofrece caminos inéditos para las sociedades actuales, pero que posiblemente fueron recorridos en épocas ancestrales.

La segunda cuestión subyacente a los alcances de esta investigación, germina justamente en esa multiplicidad de cosmovisiones que sobre el cuerpo han ido entrecruzándose con paradigmas tales como el de los patrimonios: enraizados como conciencias colectivas que se manifiestan en usos inconscientes y más recientemente, estratégicos. Es allí donde los estudios antropológicos, sociológicos, sicológicos e históricos acerca del cuerpo, provocan una efervescencia que no es ajena a las prácticas e investigaciones en educación física y artes (Pedraza, 2009) ${ }^{9}$. Si en su génesis las ciencias sociales consideraron el tema de la cultura como principio definitorio de los patrimonios, actualmente las investigaciones sobre corporalidades se multisituan interdisciplinariamente en los ámbitos de interacción cotidiana. En tal momento, aún sosteniendo la idea de invención de los patrimonios (Agudo, Op.cit.) para crear naciones y repúblicas, nos encontraríamos en un ámbito que nos permite el placer de jugar conceptualmente, ahora si aprovechando la herencia que nos hace comunes a las personas: la libertad de itinerar.

Un ejemplo de estas itinerancias conceptuales para pensar en los patrimonios corporales lo ofrece el estudio de la cultura corporal. Rubiela Arboleda, educadora física y antropóloga se ha dedicado a este emprendimiento de conjugar cuerpo-cultura. A partir de allí propuso que la cultura corporal es:

(...) la manera contundente en que cada estructura social y cultural ha marcado al cuerpo; ello connota un concepto de éste último, que ha desbordado a la organicidad y ha comprometido al entorno que lo acuna. Entre cuerpo y cultura se ha generado una relación en la que ambas partes se han permeado y se han co-construido, lo que ha dejado improntas susceptibles de rastrear; ha interesado aquí, desde el cuerpo, caracterizar la cultura en su matriz identitaria. El cuerpo, en este caso, ha estado expresando el paso de la cultura y su diario acontecer en: percepciones, actitudes, prácticas y representaciones (Arboleda, 2009a: 3)

En su trabajo, Arboleda tiene en cuenta la imbricación de la memoria que hace del cuerpo un registro del contexto cultural (Arboleda, 2009b). Es desde esta perspectiva que

\footnotetext{
${ }^{9}$ La autora identifica por lo menos dos líneas de estudios sobre corporalidades en América Latina. La primera se refiere a la instrumentalización política en tanto creación simbólica. La segunda refiere a una dimensión subjetiva expresada en las prácticas y usos recientes de los cuerpos (Pedraza, 2009: 75- 77).
} 
no podemos negar que las culturas corporales han estado colonialmente subyugadas. Ello ha legitimado la pérdida de memorias e identidades corporales, bajo el influjo de una supuesta pertenencia a un Estado-Nación. Sin embargo, frente a la actual caída paulatina de las conciencias nacionales, el sendero de las culturas corporales nos puede ayudar para analizar la manera como en los tiempos actuales asistimos a diversas búsquedas identitarias. Es la descripción de un constante reencuentro con "lo propio" y con lo que puede identificar a una persona en el contexto donde se mueve. Este despertar ante la creencia de los pueblos sin identidad evoca la "gente sin historia", que Eric Wolf (2005) refirió en el contexto del dominio de Europa.

Pero en este acercamiento a "las raíces", operado actualmente por personas, familias, comunidades, instituciones y organizaciones, perduran las desigualdades sociales y económicas impuestas por las sucesivas colonizaciones (Panqueba, 2012b). Tales desigualdades trascienden el nacimiento de las repúblicas americanas a principios del siglo XIX y se fortalecen durante el siglo XX. En el siglo XIX muchas de las expresiones étnicas pasaron a conformar los marcadores identitarios nacionales. A través de procesos de folclorización, cada nación apropió manifestaciones ancestrales y las proyectó como imagen de identidad. Similar destino fue endosado a algunos juegos de los pueblos indígenas, los cuales entraron a hacer parte del menú nacionalista.

Considerando las ambigüedades con respecto a la visibilización de las diversidades en un ambiente que en apariencia propende por la homogeneización, y pensando sobre todo en la Educación como institución legitimadora del pensamiento "universal", la pregunta central de esta investigación ha sido delimitada en los siguientes términos: ¿Cómo han sido y cómo están siendo circulados los patrimonios corporales ancestrales en Bogotá: territorio muisca de Bosa, tomando el caso de las relaciones interculturales entre institución y comunidad educativa del Colegio San Bernardino IED?

Con las dinamizaciones actuales de las identidades étnicas, demandas inéditas se avizoran repletas de cosmovisiones que no necesariamente se oponen a las necesidades de nombrar el mundo desde una perspectiva universal. Son perspectivas que más bien alimentan, complementan, fragmentan y re-significan multiversos desde sus propias historias y cotidianidades. Sin embargo no es menos cierto que persistan ciertos intereses 
de manipulación sobre las herencias simbólicas y prácticas ancestrales de los pueblos, con el fin de crear nación e imaginar comunidades. Es una una neo-colonización ejercida desde institucionalidades que utilizan el interés global por el patrimonio, el ecologismo y la supuesta característica indígena que le relaciona con el cuidado de la naturaleza (Díaz Polanco, 2006: 156- 171). Entonces el reto actual que tienen las iniciativas de re-significación de juegos ancestrales, es ver más allá del juego en su versión deportiva o como potencial de exotismo para el turismo o el folclor. Los relatos de los escritos prehispánicos nos ubican en reflexiones actuales, en la medida que expresan una conexión de eventos lúdicos, donde más que una primacía de los gestos del juego, nos reflejamos como homo ludens, en el sentido propuesto por Huizinga (1987). Los esfuerzos por reinventar, incorporar, re-crear o practicar los patrimonios corporales ancestrales, ha de considerar todos los elementos legados desde tiempos inmemoriales, pero también recoger las innovaciones de cada tiempo (Panqueba y Montaño, 1997).

\section{Con-juegos multiculturales del surrungosungo que habló el abuelito.}

Hacia finales de la década de 1990, entre las reivindicaciones étnicas de la comunidad indígena muisca de Bosa era evocada la práctica de "juegos tradicionales" como el bocholo, el tejo y la taba, entre otros. Las demandas de reconocimiento político, social y cultural fructificaron en el año 1998, cuando el Gobierno colombiano reconoce legalmente al Cabildo Indígena Muisca de Bosa como organización étnica ${ }^{10}$. A partir de entonces la comunidad fue reorganizándose en torno al "rescate" y "revitalización" de sus herencias ancestrales; las cuales estaban expresadas principalmente en la preparación de alimentos, la medicina tradicional, los bailes, la música, los juegos y la elaboración de tejidos. Posteriormente surgieron iniciativas en torno a la cerámica, las cuales ampliaron los rangos de alcance para las demandas iniciales. Las danzas y la música, tomaron la delantera gracias a la iniciativa de jóvenes muiscas que priorizaron su práctica como un camino de recordación cultural e identitaria (Panqueba, 2006).

\footnotetext{
${ }^{10}$ La figura del Cabildo, corresponde a una forma de organización comunitaria. Las comunidades indígenas la re-significaron y apropiaron, constituyéndola como el baluarte principal contemporáneo, de su base organizativa. En este sentido, la Ley 89 de 1890, reconoce el Cabildo, como el organismo de autoridad de las comunidades indígenas.
} 
En el año 2000 iniciamos una cooperación entre comunidad educativa e institución escolar. Se alimentaron mutuamente los trabajos del Cabildo Muisca de Bosa con los del colegio San Bernardino (Panqueba y Peralta, 2010). En la clase de educación física fueron incorporadas las danzas de los territorios andinos principalmente, complementando la experiencia con bailes practicados por los pueblos indígenas amazónicos, además de otros ritmos musicales convencionales de la época: salsa, merengue, vallenato y champeta. La educación física fue convirtiéndose en un espacio de experimentación, de indagación y de reflexiones desde una cosmovisión u'wa, sobre todo considerando la procedencia indígena u'wa del profesor a cargo. También surgieron otros espacios extra-escolares en los que interactuaban las mujeres y los hombres mayores de la comunidad. Viajamos por los territorios de estudiantes y docentes, así como a través de las memorias inmediatas de las abuelas y los abuelos muiscas. Fue allí que la voz del abuelito Victor Chiguasuque ${ }^{11}$ proyectó el actual camino de su nieto Oswaldo, creador musical y proponente de un interesante hito musical de la gente muisca de Bosa actual: Surrungosungo, habló el abuelito para referirse al ritmo musical y de baile que ha identificado a la gente muisca de Bosa, por lo menos durante el siglo $\mathrm{XX}$.

Entretanto, nuestras fuentes de consulta se trasladaron de los libros a los sitios sagrados, a las lagunas, las montañas y otros entornos pletóricos de bibliotecas ancestrales que nos ofrecieron en piedra, los escritos de las mujeres y los hombres muiscas que itineraron estos territorios en otros tiempos. Entonces tuvieron lugar unos talleres, ensayos y presentaciones de "danzas muiscas" que perfilaron un enfoque multicultural de investigación. La costumbre de observar la superposición mecánica de unos hechos que venían sucediendo en el territorio nos condujo a pensarnos desde la hibridación cultural (García Canclini, 1999), el sincretismo y la glocalización. El título de un texto escrito en ese tiempo así lo corrobora: “Danza glocal del 'otro' lado de Bogotá: Una experiencia de re-creación cultural desde ritmos andinos colombianos en la comunidad indígena de Bosa" (Panqueba, 2005) ${ }^{12}$.

\footnotetext{
${ }^{11}$ Sea esta mención a su nombre, un homenaje y un agradecimiento por sus palabras-guía y luz para un trabajo previo sobre la historia de la educación en el territorio muisca de Bosa (Panqueba, Peralta y Huérfano, 2012).

12 Una actualización del mismo está incluida en Panqueba, 2006 (pp. 74- 95), sin embargo la versión que mantendremos como referente para el presente documento será la del año 2004, por tratarse del documento específico sobre el tema de la danza.
} 
El rescate y re-creación cultural hicieron parte de las "responsabilidades" que nos endosamos en tanto agentes indígenas y no-indígenas. Buscábamos recuperar tradiciones, rescatar culturas, revitalizar idiomas y etno-educar. Esta combinación entre docenciaactivismo- participación- indagación, estaría enmarcada en el enfoque metodológico de la Investigación-Acción-Participante (IAP). Acciones que atisban una posición asistencialista en nuestros ejercicios iniciales de docencia, fincados en el espíritu "rescatista" de finales del siglo XX. Paradójicamente en aquellos acercamientos comprendimos que asistíamos a nuestro propio rescate (Panqueba y peralta, Op.cit.: 67-69).

Desde aquella perspectiva continuamos nuestra u'wboniná (o minga) en la que conjugamos cosmovisiones u'wa y experiencias muiscas. Entonces emerge con fuerza urá istanakr, expresión u'waka para denotar una relación de amor donde existen los mismos propósitos, ideales y pensamientos, pero diferenciados por las experiencias, el género y las capacidades de cada persona. Urá es el corazón pero también el poder, la razón y el abdomen. Regularmente la palabra no es empleada sola, siempre va unida a otra para expresar pesar (urá shirthiro), pureza (urá kesa), tristeza (urá buto rehjecro), evaluar-mirar el corazón (urá wajitró), juicioso (urá sejwac biró), arrepentirse-cambiar de corazón (urá tejhmonro), agradecimiento, tener buen corazón (urá ayro).

Para que exista algo, es necesario que exista unido. Por eso decidimos exponer acá el juego entre personas, pensamientos, sentimientos, experiencias y grupos como: conjuego. Esta es la propuesta de análisis que evocamos para significar, que si bien existen perspectivas interculturales colectivas, no deben ser olvidadas las subjetividades de cada persona. Urá istanakr para la que son necesarias las individualidades. Este argumento probablemente contradice la supuesta relación de "lo indígena" como colectivo. Sin embargo no debe ser entendido dentro de los acontecimientos políticos que han colocado "lo colectivo" como estrategia individual de supervivencia, fenómeno analizado como etnicidad estratégica (Baud, et al, 1996). Más bien como una forma de entender que a partir de las subjetividades se construye el colectivo creador para con-jugar los saberes.

Nuestros patrimonios corporales ancestrales han estado fluctuando entre colectividades, pero también entre individualidades. Un con-juego entre multiculturalidades e interculturalidades, donde los colectivos son alimentados por apuestas individuales, pero 
donde también los individuos se forman como colectivos: se unen (urá istanakr). Es un conjuego en el que han fluctuado desde tiempos inmemoriales, los préstamos, las asociaciones, las adaptaciones y evocaciones mutuas. Por eso a continuación exponemos los pasos que nos han permitido con-jugar los marcos epistémicos ancestrales con los occidentales, las experiencias ancestrales con las actuales, las formas de vida centradas en la tierra como espacio de producción agrícola, con las formas de vida en las urbes: El mundo es un territorio-laboratorio de con-juegos. Desde esta perspectiva, la presente investigación aprehendió las itinerancias territoriales como procedimiento metodológico. Quien itinera, con-juega y conjuga en su recorrido los aprehendizajes, acogiendo todos aquellos otros con-juegos que se encuentran en el camino.

\section{Zepcuagoscua, etnofagia y etnicidades estratégicas en el territorio} muisca de Bosa

Recorrer el territorio, caminarlo, echarse a andar, se constituye en metodología de investigación cuando consideramos el moverse como un fundamento de vida. Desde esta perspectiva compartimos las pedagogías interculturales que hacen parte de MuisKanoba ${ }^{13}$, una metodología de investigación- aprehendizaje producto de emprendimientos previos en otros contextos de diversidades étnicas como Bogotá (Panqueba y Peralta, Op.cit; Panqueba y Huérfano, 2006) y Chiapas, México (Panqueba, 2010). A través de las pedagogías de las contemplaciones, las descripciones, las memorias de la vida cotidiana, las revisiones históricas, las confluencias y las cuencas de los descubrimientos, MuisKanoba define el territorio como un principio constitutivo y dinámico en constante movimiento e intercambios naturales y vivos. Estos confluyen unos con otros por razones de vida: la tierra, el paisaje, el cosmos, las personas y sus historias cotidianas. Cada uno tiene en su interior, en su alma, conocimientos, lenguajes, memorias, códigos y señales que marcan senderos de conocimientos y sabidurías, los cuales se constituyen en patrimonios físicos y humanos ávidos de consulta y aprehendizajes.

\footnotetext{
${ }^{13}$ MuisKanoba (sangre del alma de la gente) es una propuesta de investigación- aprehendizaje des-cubierta en territorio del pueblo muisca, y aprehendida de abuelas y abuelos que legaron sus conocimientos en palabras, grafías, pictogramas, juegos, costumbres y prácticas de vida cotidiana.
} 
Esta construcción metodológica viene en fermento a partir del año 2001 cuando, aprovechando la interacción cotidiana con las abuelas, los abuelos y las familias muiscas, encontramos en el zepcuagoscua o juego del tejo o turmequé, nuestro siguiente camino de itinerancia. Ello se sucedió durante un ejercicio de interculturalidades que a finales de aquel año 2001, resultó en la génesis del nuevo ciclo de festividades que habían venido sufriendo transformaciones. Docentes del colegio y familias de la comunidad nos involucramos para convocar la participación del vecindario, personas, empresas y grupos culturales. "Ya no era una fiesta campesina en la periferia de una gran urbe: era el festival de los muiscas" (Panqueba, 2011: 133). Es en ese contexto que el zepcuagoscua nos acoge para ofrendarnos los saberes de las arcillas y las corporalidaes.

Zepcuagoscua es una palabra de raíz lingüística chibcha que traduce al castellano la acción de divertimiento a través del juego. Aunque en esta categoría se ubican diferentes actividades lúdicas, los juegos de lanzamiento son las que han caracterizado a las poblaciones chibchas. El zepcuagoscua, tejo o turmequé es ejemplo de ellos. El juego consiste en lanzar un disco metálico a una distancia de aproximadamente 20 metros, con el objetivo de introducirlo en un aro también metálico de unos $11 \mathrm{~cm}$ de diámetro, el cual está ubicado en el centro de un montículo de barro contenido en una caja de madera. Contemporáneamente son ubicados sobre los bordes del aro receptor, unos pequeños envoltorios de papel con pólvora en su interior. Al contacto con el disco lanzado por un jugador, se produce un estallido característico de este juego.

El zepcuagoscua fue practicado en forma ritual (sagrada) entre los pueblos prehispánicos pertenecientes a la familia lingüística Chibcha. Durante los tiempos de "conquista" y “colonización” hispánica, el zepcuagoscua se transformó. Posteriormente ha devenido en una práctica popular asociada al consumo de chicha y otras bebidas fermentadas (desde el mercado cervecero, una práctica antihigiénica). Pese a ello, esta manifestación corporal prehispánica fue tomando forma organizativa para su práctica a partir de la década de 1960, cuando fue incluido el deporte del tejo en los juegos nacionales. Si bien este paso pudo representar un hipotético descarte de su carácter ceremonial, hizo que ganara una organización para su práctica y en consecuencia una población adepta y practicante. Esta situación hizo posible un juego de apropiación a cargo de ciertas élites para resaltar el 
nacionalismo colombiano, obteniendo en consecuencia poder simbólico en la arena política $^{14}$. Este es el caso del proyecto de ley mediante el cual esta práctica fue declarada en el Congreso Colombiano como "deporte nacional"15. El acontecimiento se presenta con claroscuros si nos aferramos a la idea crítica pero válida en torno a la creación de identidad nacional en tanto "comunidad imaginada" (Anderson, 1991). Ello no impidió que identificáramos la oportunidad de hacer válida su práctica escolar pese al estigma de sentido común que liga al tejo como vicio que induce al consumo de bebidas embriagantes.

Como consecuencia de la Ley del tejo como deporte nacional, se supondría su promoción comunitaria y escolar, por lo menos a través de la organización de espacios y la adquisición de los elementos para su práctica en los colegios. Ante la imposibilidad real de lograr dicho estatus $^{16}$, propusimos las itinerancias territoriales como estrategia: visitando las canchas de tejo ubicadas por doquier en las zonas aledañas, así como el uso de canchas cuyo uso es familiar. Organizamos aquellas itinerancias a pesar de la existencia de normas que castigan la presencia de jóvenes menores de edad en los sitios donde se expenden bebidas embriagantes, situación recurrente en los campos para el juego del tejo.

Encontramos oposición para entrar en las canchas, dada la fuerte estigmatización del tejo, la cual lleva a hacer interpretaciones erróneas de normas como el código único de policía. En dicha norma, si bien no es literalmente perseguida la presencia de jóvenes en las canchas de tejo, el texto alude a los sitios de práctica de juegos, así donde se expenden bebidas embriagantes ${ }^{17}$. Estos apartados son recurrentemente citados e interpretados por autoridades, propietarios de las canchas y comunidad educativa para señalar de manera jocosa -pero con acusación subrepticia- la presencia de estudiantes del colegio en canchas de tejo para tomar una clase de educación física.

\footnotetext{
${ }^{14}$ Este caso ilustraría ejemplarmente la siguiente afirmación: "Con frecuencia, (...) [la inclusión de elementos en las listas de UNESCO] no es representativo de la diversidad y riqueza cultural de un país, sino de la capacidad de los actores institucionales para identificar y gestionar las expresiones que consideran sobresalientes, o aquellas que resultan convenientes de promocionar por razones políticas o económicas (Villaseñor y Zolla, 2012: 83).

${ }^{15}$ El tejo fue declarado "deporte nacional" según Decreto- Ley 613 DE 2000 (septiembre 4): "por la cual se declara a la disciplina del tejo como deporte nacional y se dictan otras disposiciones". La ponencia fue presentada por el entonces senador Edgar Perea y elaborada por Plinio Mendoza.

${ }^{16}$ Valga comentar que en los colegios oficiales difícilmente es considerada la dotación de implementos deportivos. Por ejemplo en el colegio San Bernardino tuvo que transcurrir más de una década para que algunos elementos fueran adquiridos a través de los recursos institucionales.

${ }^{17}$ Acuerdo 79 de 2003, por el cual se expide el código de policía de Bogotá D.C, sobre todo en los apartados relacionados con los menores de edad y su acceso a los lugares de juego y en donde expenden bebidas embriagantes.
} 
Tal como sucedió con la con-jugación de las danzas en la comunidad y en el colegio, el zepcuagoscua si bien empezó a ser parte de los contenidos de la clase de educación física, no revistió un tema de análisis como patrimonio corporal ancestral. Fue más bien un objeto de uso pedagógico que aprovechamos para diversificar los contenidos escolares. El zepcuagoscua fue mencionado, leído y jugado por docentes y estudiantes, pero también entre docentes y personas de la comunidad, cuando tenían lugar ciertas eventualidades. Fue un acercamiento estratégico tal vez en la línea que el antropólogo Héctor Díaz Polanco conceptúa como etnofagia (Díaz Polanco, 2006 y Patxi, 1999). Este término, acuñado desde la década de los años noventa del siglo XX, describe las formas en que el capitalismo neoliberal alimenta su funcionamiento a partir de la presencia de diversidades étnicas en sus contextos de intervención. Lejos de constituir un ataque violento a las diversidades, es un acercamiento de seducción, pero también de transformación y disolución de las diferencias (Díaz Polanco, 2006: 161). Fenómeno también definido como "proceso de etnocidio cultural, por medios más simulados y a largo plazo" (Patxi, 1999: 537).

Desde esta investigación, definimos como etnofagia la promoción, por medios respetuosos de los derechos humanos (sobre todo los de primera generación), de la integración y la asimilación de las poblaciones étnicas que hacen parte del Estado Nación. El proceso etnofágico es característicamente multiculturalista frente a los patrimonios étnicos: tolerante con las diversidades occidentales-liberales-capitalistas. Pero de acuerdo a los usos de las diversidades que realizan algunas personas y grupos, indígenas y noindígenas, la etnofagia también puede ser una estrategia desde discursos altermundistas. Unos hacen de "lo étnico" su forma de vida, fortaleciendo la conciencia y acciones para con los pueblos, familias y personas indígenas. Pero otros mantienen manejos ambiguos o "usos de la diversidad" (Geertz, 2001: 65- 75), que unas veces se tornan en esencialismos culturales, otras veces en posiciones relativistas, y otras veces en "anti-antirelativistas" (Geertz, 2001: 91).

Unos y otros manejos pueden ser leídos desde la perspectiva de los patrimonios, como usos de las identidades indígenas. Es decir como esencialismos estratégicos (Spivak, 1985) que pueden ser aprovechados en las instituciones educativas. Si bien son usos tal vez derivados de procesos etnofágicos, no dejan de ser estratégicos y, en consecuencia, 
presentar niveles de acción, más que de simbolismo. El contexto escolar se presenta así como un campo en el que los patrimonios se han movilizado como simbólicos para la creación de pertenencia nacional, pero en el que las acciones son razón de ser y en consecuencia, generar sus propios giros.

\section{Con-jugando entre arcillas y tejidos, los patrimonios corporales mayas} y muiscas.

Frente al problema de estigmatización del zepcuagoscua en tanto acto propicio para el consumo de cerveza, buscamos alternativas desde nuestras cosmovisiones de Abya Yala. Es así como podemos afirmar que para los pueblos indígenas andinos colombianos, verbigracia el u'wa y el muisca, el zepcuagoscua representa un ritual familiar en torno a la comida, el juego y la danza. Como práctica que requiere fuerza y precisión, en ese escenario ritual tienen lugar otros juegos que responden a re-significaciones, con el fin de hacerlo más accesible a las mujeres, niñas y niños. Actualmente contamos con variantes como el bocholo, el mini-tejo, la rana y la bolirana, entre otras que no hubieran sido posibles sin las adecuaciones que de manera creativa surgen entre sus practicantes. Aunque estos juegos fungen como espacios de aprendizaje, son variantes de una confluencia mayor, una conjunción que evidencia las habilidades ancestrales para adaptar, re-crear y re-producir una práctica corporal ${ }^{18}$. En estas vetas identificamos las oportunidades y necesidades de confluir hacia los florecimientos de los patrimonios corporales ancestrales.

Con los aprehendizajes recorridos en territorio muisca, iniciamos contactos con poblaciones mayas en Chiapas (México) y en Guatemala. Entre 2007 y 2009, junto a las niñas y los niños mayas-ch'oles del norte de Chiapas, realizamos intercambios de danzas, gracias a sus maestras y maestros con quienes compartimos jornadas de bailes de los Andes (Panqueba, 2010). Allí nos encontramos con el trabajo que personas, instituciones y comunidades adelantan desde hace dieciséis años en Guatemala, con el fin de renovar la práctica del chaaj, juego de pelota mesoamericano (Panqueba, 2012a y 2012b).

\footnotetext{
${ }^{18}$ Acerca de la estigmatización negativa del zepcuagoscua en el inconsciente colectivo de Colombia, pero también sobre su paulatina liberación de etiquetas negativas, podemos consultar un interesante documento audiovisual en el canal youtube con el siguiente acceso web:

http://youtu.be/RCUZCfeij3c?t=10m17s
} 
El juego de pelota fue creado por los pueblos que habitaron el territorio ancestral de Mesoamérica. Evidencia material de ello son los centros arqueológicos y ceremoniales como Tikal en Guatemala, Chichen Itzá en México y Copan en Honduras, entre cientos que conforman los territorios mayas. La práctica de los juegos de pelota es vigente en Guatemala, México, Honduras y El Salvador principalmente. En México juegan Ulama en el Estado de Sinaloa; pelota tarasca en el estado de Michoacán; y pelota mixteca en México, D.F y en los Estados de Veracruz y Oaxaca. Por otra parte, el chaaj, juego de pelota maya practicado en Guatemala, comprende por lo menos tres modalidades: de cadera, muy similar al ulama de México; de antebrazo, en la cual la pelota es contactada con la cadera, el antebrazo y el muslo; y la pelota de fuego que se asimila al actual hockey, donde se emplean unos bastones de madera para contactar una bola de madera incandescente (Panqueba, 2012a).

A partir de 2011, conseguimos con-jugar dos patrimonios corporales ancestrales: chaaj y zepcuagoscua. Conocimos en Guatemala el proceso de promoción del chaaj por parte del Ministerio de Cultura y Deportes, y jugando Zepcuagoscua en Colombia durante la visita de jugadores mayas de chaaj. Por tres años hemos realizado itinerancias en Venezuela, Guatemala, México, Colombia y Ecuador, promocionando el chaaj y el zepcuagoscua, a través de alianzas estratégicas con Ministerios e instituciones privadas.

Durante el año 2011 compartimos el chaaj con la juventud del territorio muisca de Bosa en las clases de educación física del Colegio San Bernardino (IED). En el año 2012 logramos la itinerancia de cuatro jugadores mayas en Bogotá, quienes durante un mes realizaron exhibiciones en tres colegios distritales, dos departamentales y dos universidades ${ }^{19}$. La experiencia reciente del año 2013 nos permitió contar nuevamente con una delegación guatemalteca de tres personas, quienes nos ofrendaron jornadas de juegos del chaaj en el colegio San Bernardino y en la Universidad Pedagógica Nacional ${ }^{20}$. En estos intercambios vivimos con-jugando las cosmovisiones mayas y muiscas a través de la elaboración en arcilla, de piezas y elementos rituales propios del chaaj. Este proceso fue compartido a

${ }^{19}$ Estas iniciativas fueron apoyadas por organizaciones indígenas, la Universidad Pedagógica Nacional, la Universidad Libre, la Secretaría de Educación Distrital de Bogotá y la Secretaría de Cultura Recreación y Deportes a través del programa DUNT (Deportes Urbanos y Nuevas Tendencias en el Distrito).

${ }^{20}$ Además de las instituciones que apoyaron las actividades el año anterior, en esta oportunidad se vincula el Instituto para la Investigación y el Desarrollo Pedagógico IDEP. 
través de talleres de elaboración y adecuación para hacer posible la difusión posterior. No se trataba de tocar el barro y moldearlo simplemente.

En la arcilla se encuentran los cuatro elementales según los saberes muiscas: "que la gente no se embarre por embarrarse", fue el mandato de las sabedoras de las arcillas. Sus palabras insistían en que la creación es la puesta del pensamiento en una forma determinada. Aprovechando la naturaleza también intercultural de las arcillas, conjugamos los elementos de las cosmovisiones maya y muisca. Como elementos de estas cosmovisiones con-jugamos la concepción de tiempo que los ancestros y las ancestras mayas nos heredaron a través de los calendarios de cuenta corta y de cuenta larga. En las piezas interculturales logradas, comunicamos el espíritu del oxlajuj baktún ${ }^{21}$ (Panqueba, 2012b), pero también la concepción muisca sobre la vida y la muerte. Una cosmovisión que coincide con la ceremonia del juego de pelota maya, evocación de una lucha ritual entre los creadores de la vida con los señores del inframundo.

A partir de esta con-jugación, desde nuestras cosmovisiones entramos en sintonía con las cotidianidades diversas en que nos movemos. Desde una perspectiva universalizante, los actuales sucesos apuntan a varios elementos de la globalización. Tal vez una realidad multicultural, en la que el universo global reconoce y admite las diversidades pero las aprovecha en beneficio de una sola forma de nombrar y concebir el mundo. Sin embargo, resultaría fatigante una oposición que coloque en contraste a las diversidades. Ejemplo de ello es que a pesar de no estar nombradas, las matrias ${ }^{22}$ han ofrendado los territorios propicios para el florecimiento de una patria. Esta investigación es un esfuerzo por visibilizarnos desde las matrias que evocamos desde el corazón. En los aprehendizajes de los intercambios logramos con-jugarnos.

\section{Conclusiones}

La presente investigación ha tomado formas concretas que se expresaron en objetos simbólicos elaborados en arcilla. Pero uno que podemos tomar como conclusión con-

\footnotetext{
${ }^{19}$ Estas iniciativas fueron apoyadas por organizaciones indígenas, la Universidad Pedagógica Nacional, la Universidad Libre, la Secretaría de Educación Distrital de Bogotá y la Secretaría de Cultura Recreación y Deportes a través del programa DUNT (Deportes Urbanos y Nuevas Tendencias en el Distrito).

${ }^{20}$ Además de las instituciones que apoyaron las actividades el año anterior, en esta oportunidad se vincula el Instituto para la Investigación y el Desarrollo Pedagógico IDEP.
} 
jugante, es el bocholo. Un patrimonio corporal ancestral en torno al cual constituimos un objeto simbólico de uso lúdico: creamos un bocholo del siglo XXI. Un objeto que es producto de interculturalidades (es decir con-juegos institucionales), pero también de con-jugaciones cotidianas entrelazando los textiles mayas, los tejidos muiscas y las corporalidades ancestrales.

Bien es sabido y argumentado que América se ha construido con parámetros euro centristas y macroeconómicos de manera impositiva. A pesar de ello existen múltiples saberes ancestrales y parámetros de vida de nuestras culturas ancestrales que son un aporte concreto, válido y además significativo para el contexto pluri-multi- e intercultural de la sociedad colombiana. La con-jugación desde los saberes corporales ancestrales es por tanto una oportunidad de ampliar el conocimiento y valor de la escuela en general y de la educación física, el deporte y la recreación en particular. El camino lleva a nuestras cotidianidades pletóricas de formas de educar, sentidos de crear y formas de proceder y de jugar. Más allá de proponer una educación física para las interculturalidades, jugamos por la visibilización de un campo de necesaria formación en los multiversos que vivimos y desde las historias interculturales que nos cruzan y con-juegan.

\section{Bibliografía}

Agudo Torrico, Juan (2012) Patrimonio etnológico y juego de identidades. En: Revista andaluza de antropología. Número 2: Patrimonio Cultural y Derechos Colectivos. Marzo de 2012, pp. 3-24. Disponible en: http://www.revistaandaluzadeantropologia.org/uploads/ raa/n2/jagudo.pdf

Anderson, Benedict (1991) [1983]. Imagined Communities: Reflections on the Origin and Spread of Nationalism (2da. edición). London and New York: Verso.

Arboleda, Rubiela (2009a). Cultura corporal: miedo, identidad y resistencia. En: VIII Reunión de Antropología del Mercosur (RAM). "Diversidad y poder en América Latina". Buenos Aires, Argentina. 29 de septiembre al 2 de octubre de 2009. Disponible en: http:// www.ram2009.unsam.edu.ar/GT/GT\%205\%20\%E2\%80\%93\%20Corporalidad\%20y\%20 Subjetivaci\%C3\%B3n\%20en \%20el\%20mundo\%20contempor\%C3\%A1neo/GT\%20 5-Ponencia\%20[Arboleda].pdf (Consultado en mayo de 2012) 
Arboleda, Rubiela (2009b) El cuerpo: huellas del desplazamiento. Hombre Nuevo Editores, Medellín, 2009, 282 p.

Baud, Michael; Koonings Kees; Oostindie, Gert; Ouweneel, Arij y Patricio Silva (1996). $(\mathrm{Re})$ construcciones de la Etnicidad. En: Etnicidad como estrategia en América Latina y el Caribe. Quito: Abya- Yala

Díaz-Polanco, Héctor (2006). Elogio de la diversidad: globalización, multiculturalismo y etnofagia. México: Siglo XXI.

Fuentes-Pérez, lleana, "De Patria a Matria" (1997). Cuban Studies Association Occasional Papers Paper 14. Disponible en: http://scholarlyrepository.miami.edu/csa/14. (Consultado en octubre de 2013).

Geertz, Clifford (2001). Los usos de la diversidad. Barcelona: Paidós.

Huizinga, Johan (1987). Homo Ludens. Madrid: Alianza Editorial. $1^{a}$ ed., $2^{a}$ reimpr.

Kurin, Richard (2004) La salvaguardia del patrimonio cultural inmaterial en la Convención de la UNESCO de 2003: una valoración crítica. En: Museum international. N. 221/222: Intangible Heritage. UNESCO, Mayo de 2004, pp. 68-81.

Panqueba, Jairzinho (2012a) Chaaj (Juego de pelota mesoamericano): Un juego ancestral entre emergencias culturales. En: “Ra Ximhai” Vol. 8 N³ Mayo-Septiembre 2012. Número especial Interculturalidad y Paz. Revista científica de sociedad, cultura y desarrollo sostenible. Universidad Autónoma Indígena de México. Sinaloa, México. ISSN: 1665-0441. Disponible en: http://www.uaim.edu.mx/webraximhai/Ej-25articulosPDF/Art03. pdf. (Consultado en noviembre de 2013)

(2012b) Jugadores de pelota maya en tiempos del Oxlajuj B’akt'ún. En: “Lúdica Pedagógica” Revista de la Facultad de Educación Física. N¹7. Bogotá, D.C. Universidad Pedagógica Nacional.

(2011) Indígenas del "otro" lado de Bogotá, Colombia: Semblanza sobre sus memorias cotidianas e identificación histórica. En: DESACATOS N 35, Enero- Abril 2011. México: CIESAS. Disponible en: http://www.ciesas.edu.mx/desacatos/35\%20Indexado/ esquinas3.pdf

(2010) Jubilaciones del indigenismo y mercado de etnicidades en el municipio de Tila, Chiapas: sus manifestaciones en las itinerancias territoriales del 
magisterio ch'ol. Tesis de doctorado en ciencias sociales con especialidad en Antropología Social. CIESAS, Guadalajara, Jalisco (México).

(2006) El “otro’ lado de Bogotá: Memoria cotidiana e identificación histórica de la Comunidad Indígena Muisca de Bosa (Colombia). Tesis de Maestría en Ciencias Sociales con mención en estudios étnicos. FLACSO, Quito.

(2005). Danza glocal de otro lado de Bogotá: reconstrucción cultural desde ritmos andinos colombianos en la comunidad indígena muisca de Bosa. En: "Pensar la danza" Panamericana formas e impresos S.A, IDCT, Bogotá, D.C.

Panqueba, Jairzinho; Blanca María Peralta y Arturo Huérfano Méndez (2012) Revisión Histórica de la educación en el territorio muisca de Bosa, por entre sus memorias cotidianas. En: “Educación y Ciudad” N²1. Julio de 2012. IDEP. Bogotá.

Panqueba, Jairzinho y Jorge Arturo Huérfano (2006). MuisKanoba: Territorios de aprehendizajes para cotidianidades interculturales. Documento de itinerancias y aprehendizajes compartidos. Bogotá, territorio muisca.

Panqueba, Jairzinho y Víctor Montaño (1997). Una Chicha por el Juego Ancestral de los Sinúes. Tesis de Licenciatura en Educación Física. Universidad Pedagógica Nacional, Bogotá, D.C.

Patzi, Félix (1999) Etnofagia Estatal. Modernas formas de violencia simbólica (Una aproximación al análisis de la reforma educativa). Boletín del instituto francés de estudios andinos. 1999, 28 (3): 535- 559. Disponible en: http://www.ifeanet.org/publicaciones/ boletines/28(3)/535.pdf (Consultado en mayo de 2012)

Pedraza, Zandra (2009) Derivas estéticas del cuerpo. En: “Desacatos”, núm. 30, mayo-agosto 2009, pp. 75-88. CIESAS, México. Disponible en: http://www.ciesas.edu.mx/ Desacatos/30\%20Indexado/saberes_5.pdf (Consultado en noviembre de 2013)

Spivak, Gayatri Chakravorty (1985) Estudios de la subalternidad: deconstruyendo la historiografía, en S. Rivera Cusicanqui y R. Barragán (comps.), Debates post coloniales: una introducción a los estudios de la subaltenidad, Ediciones Aruwiyiri, Editorial Historias, La Paz, Bolivia.

UNESCO (2012) Register of Best Safeguarding Practices 2011. In: Intangible Cultural Heritage. United Nations Educational, Scientific and Cultural Organization. París. pp. 12- 
17. Disponible en: http://www.unesco.org/culture/ich/doc/src/17332-EN.pdf (noviembre 22 de 2013)

UNESCO (2009) Lista representativa del patrimonio cultural inmaterial de la humanidad. En: "Patrimonio Cultural Inmaterial". Organización de las Naciones Unidas para la Educación, la Ciencia y la Cultura. París. Disponible en: http://www.unesco.org/culture/ich/ doc/src/06859-ES.pdf (noviembre 22 de 2013)

UNESCO (2008a) Directrices operativas para la aplicación de la convención para la salvaguardia del patrimonio cultural inmaterial. Documento oficial disponible en: www.unesco.org/culture/ich/doc/src/00353-ES.doc (consultado en noviembre de 2013)

UNESCO (2008b) Aplicación de la Convención para la Salvaguardia del Patrimonio Cultural Inmaterial. En: "Patrimonio Cultural Inmaterial". Organización de las Naciones Unidas para la Educación, la Ciencia y la Cultura. Disponible en: http://www.unesco.org/ culture/ich/doc/src/01853-ES.pdf (consultado en noviembre de 2013)

Villaseñor Alonso, Isabel y Emiliano Zolla Márquez (2012) Del patrimonio cultural inmaterial o la patrimonalización de la cultura. En: "Cultura y representaciones sociales": Año 6, No12. Marzo de 2012, p. 75-112. Disponible en:: https://www.academia.edu/1452889/ Del_patrimonio_cultural_inmaterial_o_la_patrimonializacion_de_la_cultura (consultado en noviembre de 2013).

Wolf, Eric R. (2005) [1987] Europa y la gente sin historia. México: Fondo de Cultura Económica. 
Kwitara Santayá u'wbohiná-kueshro. Con-jugando patrimônios corporais ancestrais em Bogotá: território Muisca de Bosa.

Resumo: O trabalho apresenta a sistematização sobre o território Muisca de Bosa que segue quatro caminhos de con-jugações de patrimônio corporal ancestral. O primeiro caminho é o dos ancestrais que nos deixaram o corpo como oferenda portador de conhecimentos milenares. O segundo são os con-jogos multiculturais das danças e das músicas. $\mathrm{O}$ terceiro é o jogo do tejo ou turmequé, tomado como metodologia de investigação desde as interculturalidades de Bogotá. O quarto é o dos nossos resultados, refletidos na conjugação de patrimônios culturais ancestrais Muiscas e Maias. Finalmente compartilhamos os possíveis destinos, as con-jugações latentes e outros caminhos a serem percorridos.

Palavras chaves: patrimônios. corporalidade. ancestral. interculturalidades. jogo. educação.

\section{Kwitara Santayá u'wbohiná-kueshro. Con-jugating ancestral's body patrimonies in Bogotá: Muisca de Bosa territory.}

Abstract: The work shows the systematization in the Muisca de Bosa territory that followed four paths of ancestral body patrimony con-jugations. The first path is the one that our ancestrals left us in which the body is offered as a carrier of millenary knowledge. The second is with the music and dance multicultural games. The third is the tejo or turmeque game, as an investigation methodology for the interculturalaties of Bogotá. The fourth is the one of our results, reflected on the ancestral cultural patrimonies con-jugation of the Muiscas and Maias. Finally, we share the possible destinies, latent con-jugations and other pathways.

Keywords: patrimonies. corporeality. ancestral. interculturalities. game. education. 